\title{
Question Formation Problems Encountered by Students of English as a Foreign Language: A Case Study
}

\author{
Dr. Fatima Elnaeem Mohammed \\ Ph.D. in English language, Curriculum and Methodology; Ph.D. in General Translation, Buraydah Colleges, Saudi Arabia
}

$\square$ Corresponding Author: Dr. Fatima Elnaeem Mohammed, E-mail: fatima.elnaeem@yahoo.com

\author{
ARTICLE INFORMATION \\ Received: January 08, 2021 \\ Accepted: March 14, 2021 \\ Volume: 3 \\ Issue: 3 \\ DOI: $10.32996 /$ jhsss.2021.3.3.2
}

\section{KEYWORDS}

Question Formation, English as a forging language, Sudanese university students, linguistic levels

\section{ABSTRACT}

This study aims at identifying the problems that face Sudanese university students in forming questions for communicative purposes in the English language; it is an investigation of the difficulties the students find in constructing questions correctly and accurately. Types of errors were analyzed on different linguistic levels. The results have shown that the area of confusion includes the use of the verb 'be', present and past tense, parts of speech and word order. The methodology used in this study was based on the students' feedback; linguistic analysis of the questions they formed. The main findings proved that the students face difficulties in forming questions resulting from the fact that their first language has a significant influence on learning English as a foreign language in general and forming questions in particular.

\section{Introduction}

English language is widely used as a means of communication among speakers of other languages; it is now a global lingua franca and a leading language in many countries and regarded as dominant in many fields like education, business, and economy. It is documented that the recent development of science and technology has resulted in spreading of English language. Ammon (2001) states, "It is an established fact that progress in science depends on the accumulation of a written record of all previous science; that is science requires great information storage and retrieval systems. The invention of the computer made those information storage and retrieval systems geometrically larger and more accessible, since much of the science and technology research was conducted in English, most of the information in the information storage networks was written in English, and nearly $85 \%$ of all scientific and technological information in the world today is written and/or abstracted in English".

English for specific purposes (ESP) or academic purposes (EAP) has become an important part of English language teaching, Tom Hutchinson and Alan Waters (1987) state that English needed by a particular group of learners could be identified by analyzing the linguistic characteristics of their specialist area of work or study " tell me what you need English for and I will tell you the English that you need", according to them this became the guiding principle of ESP.

Efforts in learning English as a second language (ESL) or a foreign language (EFL) cannot always result in the acquisition of native-like fluency. Still, it can be helpful when learning is intended to meet specific needs of the learners, and generally when a principled and systematic teaching approach is used to make the students engage in role play to adjust their use of the target language to different contexts in order to create an authentic communicative environment through discourse-oriented learning.

English language is used as a means of instruction in some universities in Sudan at present, and with the obvious deterioration in English language standards in general, the students face difficulties in using English for their studies.

Questioning is an essential part of language learning. It encourages the students to understand the subject content and helps them participate in class activities. This research aims to find out how the students form questions for communicative purposes.

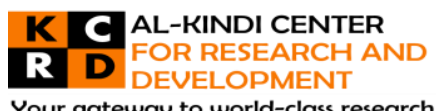

Your gateway to world-class research

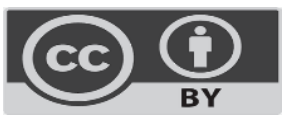

Published by Al-Kindi Center for Research and Development. Copyright (c) the author(s). This open access article is distributed under a Creative Commons Attribution (CC-BY) 4.0 license 
The main question to be answered by this research is: What are the problems and difficulties the students find in question formation when using English for academic purposes (EAP)?

The hypothesis in this research is that the students' first language interferes and causes problems while forming questions.

\section{Literature Review}

This part covers the literature related to the problems that face Arab learners of EFL in their home countries. These problems are in the four language skills (listening, speaking, reading and writing) as stated by many researchers and studies that discuss the various difficulties of language learning and the reasons behind these communication problems.

As stated in Wikipedia, the free encyclopedia, "A question is a linguistic expression used to request information, or the request made using such an expression. The information requested is provided in the form of an answer"

Types of questions in English are:

- Wh. Questions

- Yes-no questions

- Choice questions

- Question tags

- Rhetorical questions

- Indirect questions

Question formation difficulties may arise from the difference between the formation of other sentences in some ways; for example, word order is not the same in each case. English sentence begins with the subject while the question begins with a helping verb.

Questions about information begin with a question word like who, what, why, which, when, where etc. followed by the helping verb, the subject follows the helping verb and the main verb comes after the subject, and the rest of the sentence follows it.

Question words like do, does or did make no change in the meaning of a question, but it is considered an alert for the coming question.

Roger Woodham says, "We use do/does or is/are as question words when we want to ask yes/no questions. We use it with third-person singular pronouns (he, she, it) and singular noun forms. We use do and are with other personal pronouns (you, we they) and with plural noun forms".

As stated in (myenglishpages.com) "But, for today, we will simply call them "modals" or "modal verbs." "Can," "could," "may," "might," and "should" are examples of modal verbs. We form these yes or no questions with a modal verb + subject + main verb"

Modal verbs are called auxiliary verbs, they express the mood of some other verbs and ideas such as: necessity, prediction, possibility, deduction and speculation. They do not end with (e)s in the third-person singular; or having past form, participle or infinitive forms.

a. (Can) expresses ability, permission and offers.

b. (could) expresses possibility, past ability, permission and requests.

c. (may) expresses possibility and permission. -

d. (might) expresses slight possibility.

e. (must) expresses obligation and logical dedication.

Abdul Haq (1982, p. 24) states, "Arab EFL learners keep committing errors in syntax, semantics, morphology, pronunciation, and spelling". This results from the fact that Arabic and English language are different in their structure and sound system, in addition to that the first language or mother tongue interferes in the learner's efforts to learn a second or foreign language, thus it is considered the major cause or main reason behind difficulties with the new language.

Lado (1957) noted that "In comparing native and foreign language lies the key to ease or difficulty in foreign language learning. Those elements that are similar to the learner's native language will be simple for him and the different elements will be difficult". 
Jabak (2000) stated that "It is self-evident that Arabic has a different grammar system from English. Such a difference becomes transparently obvious when these two languages are compared or contrasted by means of translation". Parts of speech in English are big in number than those in Arabic which are only (nouns, verbs and articles). Word order in English is not the same as in Arabic, which constitute difficulty to the students.

Leech et al. (1924) pointed out grammar usage problems by giving opinions about grammar perspective rules such as personal pronouns usage (formal and informal), so the difficulties occur because of the conflict between these two sets of rules, the formal and informal.

Linguists tend to highlight the importance of the language recognition stage; they agreed that speaking skills are developed through listening skills for mastering the sound system and familiarize learners with intonation, rhythm and other features of the target language.

Segal (1981) suggested a new method for teaching EFL based on the following: a) Understanding the spoken language should be developed far in advance of speaking, b) Learning can and should be through movement of the teacher's and the student's body, c) Speech is natural and developmental, and will emerge naturally in its own time, d) Students should not be rushed into reading and writing before had ample listening and speaking experience.

Rivers (1966) also observed that "speaking does not of itself constitute communication unless what is said is comprehended by another person, teaching the comprehension of a speech is therefore of primary importance if the communication goal is to be reached". Therefore, speaking skills are developed through natural and informal conversation for learners in the primary stages.

Michael (1976) states that: "Foreign language teachers are likely to lay stress on the increasingly important vocational value of their subjects; or to emphasize the fact that it is needed just for the sake of education as an end, a means of communication or means of learning".

Elizaveta Pachina (2020) stated that there is a variety of problems and difficulties facing speakers of Arabic language to learn English language. This refers to the fundamental differences between the two languages. Arabic is a three-consonant rooted language, so words are formed by adding suffix, prefix or infix.

According to this, knowledge of the language is central to teaching competence, that learners at the initial stage need good models of the target language pronunciation with all other features of that language so that they might not learn bad habits that are difficult to overcome. Teachers should also be aware of the importance of knowing the differences between the foreign language and the mother tongue, which can help them in many ways, such as identifying errors and reviewing these errors diagnostically to look for solutions.

\section{Methodology \\ 3.1. Subjects}

To achieve the objectives of this research, a number of students (20) who study English language at different Sudanese universities were taken as a random sample. Their age ranges from 19 to 23.

\subsection{Data collection procdure}

To reach the actual problems of forming questions that the students face while using English language in different settings, a tool of data collection is utilized to achieve this study's goals by analyzing sample questions of the students. These questions represent the corpus of this study. The students were asked to form questions from a course reading (the model answers were given to them), these questions will be analyzed, and findings will be explained to enable the researcher to build suitable recommendations upon them.

\subsection{Data analysis Procedure}

The students' questions of the given answers were collected.

A table was designed in a special way for this study and divided into two parts showing (the student's questions and the errors), to be discussed and analyzed on a linguistic base.

\section{Results and Discussion}

The present research is concerned with analyzing errors in question formation usually committed by university students, to accomplish the purpose of this research, collected data (students' questions) is analyzed and classified according to different linguistic levels. 
Table (1): Errors in question formation:

\begin{tabular}{|l|l|l|}
\hline & Students' questions & Error \\
\hline 1 & $\begin{array}{l}\text { What the problem? } \\
\text { What problem? }\end{array}$ & Omission of verb = is \\
\hline 2 & How the effects? & Omission of verb = are \\
\hline 3 & The student not happy? & Omission of verb = are \\
\hline 4 & Do you sure? & Using do in place of are \\
\hline 5 & What was happen first? & Addition of verb = was \\
\hline 6 & When it was? & Word order \\
\hline 7 & When you can come? & Word order \\
\hline 8 & Where..... they searched first? & $\begin{array}{l}\text { Omission of verb = did. } \\
\text { Use of past form of the verb ( search) }\end{array}$ \\
\hline 9 & I can go now? & $\begin{array}{l}\text { Use of (can) in place of (may). } \\
\text { Word order }\end{array}$ \\
\hline 10 & Is it orally exam? & Incorrect use of the word (oral) \\
\hline 11 & Is he died? & $\begin{array}{l}\text { Use of verb(died) in place of adjective } \\
\text { (dead) }\end{array}$ \\
\hline 12 & Are they full with...... & Use of (with) in place of preposition(of) \\
\hline
\end{tabular}

All questions in the table above show samples of errors in question formation, first is the use of the verb 'be'. These results show that most EFL learners face linguistic problems that refer to differences between the two languages' structures. Sentence constituents are different in English and Arabic, in the latter, a sentence can be formed without a verb, this reflects when a question is formed by the students as in the first and second examples, ignoring the verb 'be' is clear evidence for that. The verb "was" is used to express the past and this is similar to the way it is used in Arabic, thus, using the verb 'be' in the present tense or past poses difficulty to the students when forming questions because it has no equivalent in Arabic, therefore, it is omitted when an English question is produced.

English and Arabic have different grammar rules, so problems arise from these differences. The past form is the base of any given the word in Arabic (three letters verb), while in English the past is formed by adding (ed) in regular verbs. This study's questions show how the students failed to form questions in English correctly. Past tense poses difficulty to the students, the verb 'was' is used before the main verb of the sentence, the reason is that in Arabic a particular verb precedes the present to form the past, this verb is similar in meaning to the English word (is/was).

Word order in English is different from that in Arabic, another difficulty the students encounter in question formation, this can be attributed to the fact that there are no helping verbs in Arabic, (When it was?) and (When you can come?) making questions in this way is piece of evidence for interference of first language and colloquial Arabic in using English in general and forming questions in particular.

When forming an English question, usually modal verbs precede the noun, while in Arabic the word /hal/ is followed by a verb to make a meaningful question, these verbs give the same meaning as the English modals when used in different contexts, but these verbs are used in the wrong place by the students who tend to use the verb (can) instead of (may), this refers to the influence of mother tongue as we find in the examples above.

Adverbs in Arabic end the sentence in most cases, but in English, it takes different positions, which causes confusion and results in incorrect questions.

Using English preposition is difficult due to the different meanings of each one. Many English prepositions have no equivalents in Arabic, most of the problems faced by the students arise from this difference.

\section{Conclusion}

The significance of this study is that it concentrated on identifying the problems that Sudanese university students encounter in forming questions for communicative purposes in English language, thus, investigating the difficulties the students find in constructing questions correctly and accurately.

Regarding the question about the problems and difficulties the students find in question formation when using English for academic purposes (EAP), the student's questions were analyzed and the main findings are as follows: 
a. Grammatical difficulties are the main reasons behind the problem e.g. the use of the verb 'be' is one of the reasons behind the difficulty to the students when forming questions in English, using the verb "was" in a question also causes difficulty to the students because it has no equivalent in Arabic; therefore, it is omitted when an English question is produced.

b. Word order is one of the difficulties the students encounter in question formation, and this can be attributed to the fact that there are no helping verbs in Arabic.

c. Using English adverbs and prepositions in English questions pose difficulties due to the differences between the two languages.

The results show that university students' problems in forming questions in English refer to the difference between Arabic and English. The students' tongue interferes in their efforts to produce good language.

Recommendations:

Based on the results of this study, suggestions and recommendations come to help students overcome the difficulties they find in questions formation through continuous practice of the language in real situations, curriculum planners and syllabus designers should give special attention to language learning outcomes, periodical review is required and feedback to be utilized for improvement. Language instructors should encourage the students to develop their language skills through various activities for better language learning.

\section{References}

[1] Abdul Haq, F. (1982). An analysis of syntactic errors in the composition of Jordanian secondary students. Unpublished MA Thesis. Jordan. Yarmouk University.

[2] Ammon, U. (Ed.). (2011). The dominance of English as a language of science: Effects on other languages and language communities (Vol. 84). Walter de Gruyter.

[3] Hutchinson, T., \& Waters, A. (1987). English for specific purposes. Cambridge university press.

[4] Lado, R. (1957). Linguistics across cultures: Applied linguistics for language teachers. University of Michigan press.

[5] Jabak, O. (2007). Analysis of the most commonly recurring difficulties facing Arab students when translating into English. [Unpublished master's dissertation]. University of Salford. UK. 